\title{
Terahertz Absorption Spectroscopy of Benzamide, Acrylamide, Caprolactam, Salicylamide, and Sulfanilamide in the Solid State
}

\author{
Ye Jiang, ${ }^{1}$ Fengshan Zhou, ${ }^{2}$ Xiaodong Wen, ${ }^{3}$ Limin Yang, ${ }^{3}$ Guozhong Zhao, ${ }^{4}$ He Wang, \\ Haiyan Wang, ${ }^{4}$ Yanjun Zhai, ${ }^{1}$ Jinguang Wu, ${ }^{5}$ Kexin Liu, ${ }^{3}$ and Jia'er Chen ${ }^{3}$ \\ ${ }^{1}$ College of Pharmacy, Liaoning University of Traditional Chinese Medicine, Dalian 116600, China \\ ${ }^{2}$ School of Materials Science and Technology, China University of Geosciences, Beijing 100083, China \\ ${ }^{3}$ State Key Laboratory of Nuclear Physics and Technology, Institute of Heavy Ion Physics, School of Physics, Peking University, \\ Beijing 100871, China \\ ${ }^{4}$ Department of Physics, Capital Normal University, Beijing 100037, China \\ ${ }^{5}$ The State Key Laboratory of Rare Earth Materials Chemistry and Applications, College of Chemistry and Molecular Engineering, \\ Peking University, Beijing 100871, China \\ Correspondence should be addressed to Fengshan Zhou; zhoufs@cugb.edu.cn and Yanjun Zhai; lnzyzyj@sohu.com
}

Received 6 September 2013; Accepted 14 December 2013; Published 16 February 2014

Academic Editor: Yizhuang Xu

Copyright (C) 2014 Ye Jiang et al. This is an open access article distributed under the Creative Commons Attribution License, which permits unrestricted use, distribution, and reproduction in any medium, provided the original work is properly cited.

\begin{abstract}
Terahertz (THz) absorption spectra of the similarly structured molecules with amide groups including benzamide, acrylamide, caprolactam, salicylamide, and sulfanilamide in the solid phase at room temperature and $7.8 \mathrm{~K}$ for salicylamide are reported and compared to infrared vibrational spectral calculations using density functional theory. The results of THz absorption spectra show that the molecules have characteristic bands in the region of $0.2-2.6 \mathrm{THz}\left(\sim 7-87 \mathrm{~cm}^{-1}\right)$. THz technique can be used to distinguish different molecules with amide groups. In the $\mathrm{THz}$ region benzamide has three bands at $0.83,1.63$, and $1.73 \mathrm{THz}$; the bands are located at 1.44 and $2.00 \mathrm{THz}$ for acrylamide; the bands at 1.24, 1.66 and $2.12 \mathrm{THz}$ are observed for caprolactam. The absorption bands are located at $1.44,1.63$, and $2.39 \mathrm{THz}$ at room temperature, and at $1.22,1.46,1.66$, and $2.41 \mathrm{THz}$ at low temperature for salicylamide. The bands at 1.63,1.78, 2.00, and $2.20 \mathrm{THz}$ appear for sulfanilamide. These bands in the $\mathrm{THz}$ region may be related to torsion, rocking, wagging, and other modes of different groups in the molecules.
\end{abstract}

\section{Introduction}

Spectroscopy is a powerful technique for measuring, analyzing, and identifying various molecules. Frequencies in the far-infrared (FIR, 650-50 $\mathrm{cm}^{-1}$ ) and terahertz (THz) (0.1$10 \mathrm{THz}$, or $3.3-333.6 \mathrm{~cm}^{-1}$ ) ranges correspond to motions of the entire molecular structure, involving relatively large masses and relatively shallow potentials $[1,2]$. THz spectroscopy is being used for a number of important analytical applications in such areas as threat detection [3-5] and pharmaceutical characterization [6-8]. Its utility stems from solid-state compounds and molecules containing low-energy vibrations that, taken as a whole in this region, serve as spectral "fingerprints" usable for their detection and characterization. THz spectroscopy of condensed-phase biological samples are investigated ranging from the simple crystalline forms of amino acids, carbohydrates, and polypeptides to the more complex aqueous forms of small proteins, DNA, and RNA [9-14]. THz hydration studies uncovered that the dynamical hydration shell of saccharides consists of several hundred water molecules and up to thousand water molecules for proteins [15-17]. THz spectroscopy is regarded as the renaissance of far-infrared spectroscopy [18].

Amide groups contribute significantly to the protein structure. A variety of techniques such as IR, NMR, Raman, ultrasonic absorption, and UV/Vis spectroscopies have been used to characterize both the intermolecular and intramolecular bonding in amide compounds [19-22]. Salicylamide is a nonsteroidal anti-inflammatory agent with analgesic and antipyretic properties. Its therapeutic action and potential 
toxicity are still the subject of research, which makes it necessary to control its presence in biological fluids [23]. For acrylamide, it is found that its administration to laboratory animals caused tumor formation in various organs, the exact mechanism involved still being unclear [24, 25]. Sulfanilamides are successfully employed as effective chemotherapeutic agents for the prevention and cure of bacterial infections in human biological systems. Determination of molecules with amide groups is essential in many analyses of biological and clinical applications.

Here we have investigated the low-frequency vibrational motions of salicylamide, benzamide, acrylamide, caprolactam, and sulfanilamide in the solid state by concentrating on the spectral region between 7 and $650 \mathrm{~cm}^{-1}$ where crystal lattice vibrations, hydrogen bond bending modes and collective modes, and so forth may occur [26]. The experimental results indicate that FIR and $\mathrm{THz}$ time-domain technique can be effective tools to detect different molecules with amide groups and the bands in the region may be related to torsion, rocking, wagging, and other modes of different groups of the molecules.

\section{Experimental}

2.1. Materials. Salicylamide, benzamide, acrylamide, caprolactam, and sulfanilamide were obtained from commercial sources and used without further purification.

2.2. Physical Measurements. The $\mathrm{THz}$ absorption spectra were recorded on the $\mathrm{THz}$ time-domain device of Capital Normal University of China, based on photoconductive switches for generation and electrooptical crystal detection of the far-infrared light. The experimental apparatus for terahertz transmission measurements has been discussed in detail elsewhere [27]. The preparation of the samples was by pressing mixed pellets with polyethylene powder (pure sample for benzamide); the diameter of the samples is $13 \mathrm{~mm}$ and the thickness of the samples is about $0.8 \mathrm{~mm}$. The detection of $\mathrm{THz}$ absorption spectra was carried out at $\mathrm{N}_{2}$ atmosphere to avoid the influence of water vapor. The resolution of the spectra is $40 \mathrm{GHz}$. The $\mathrm{THz}$ frequencydomain spectra were obtained from the corresponding $\mathrm{THz}$ time-domain spectra via Fast Fourier Transform. Through comparison of $\mathrm{THz}$ frequency-domain spectra of the samples and corresponding references, the $\mathrm{THz}$ absorption spectra of the samples were obtained. Effective spectrum range is $0.2-$ 2.6 THz, respectively.

The FIR spectra of benzamide, acrylamide, caprolactam, and salicylamide were measured using common used Nujol mull method, because mineral oil has no absorption in the far-IR region and the method can protect sample in solid state against wet and avoid distortion of bands or happening of ion exchange. Samples were suspended in the Nujol mull and then were daubed on a thin polyethylene window and another thin polyethylene window as background for comparison. Far infrared spectra in the range of $650-50 \mathrm{~cm}^{-1}$ were taken on a Nicolet Magna-IR 750-II Spectrometer at room temperature and at $8 \mathrm{~cm}^{-1}$ resolution, 128 scans. The optical bench was purged with dried air. The FIR spectrum of sulfanilamide was measured on a Bruker VERTEX 80v FTIR spectrometer at $4 \mathrm{~cm}^{-1}$ resolution and 32 scans. The preparation of the sample was by pressing mixed pellets with polyethylene powder.

All theoretical calculations were performed with the Gaussian 03 software package [28]. Density functional theory (DFT) calculations were used to determine the equilibrium structures and harmonic vibrational frequencies of the molecules. The B3LYP [29] hybrid density functional was used with the 6-311++G (3df, 2pd), Gaussian-type basis set [30]. Full geometry optimizations were conducted in each case and harmonic frequency analyses performed on these optimized structures.

\section{Results and Discussion}

The molecular structures of benzamide, acrylamide, caprolactam, salicylamide, and sulfanilamide are shown in Figure 1. The THz and FIR spectra of benzamide, acrylamide, caprolactam, salicylamide, and sulfanilamide are shown in Figures 2 and 3, respectively. The corresponding band positions in the FIR and $\mathrm{THz}$ absorption spectra of the samples and possible assignments are listed in Table 1.

3.1. The THz Absorption Spectra of the Molecules. All of the structures of benzamide, acrylamide, caprolactam, salicylamide and sulfanilamide have amide groups. The difference of benzamide, and salicylamide is that there is one more $\mathrm{OH}$ group in the structure of salicylamide, and both of the two molecules have benzene ring (ph). The $\mathrm{THz}$ absorption spectra of benzamide, acrylamide, caprolactam, salicylamide and sulfanilamide in Figure 2 show that in the $\mathrm{THz}$ region benzamide has three bands: $0.83,1.63$, and $1.73 \mathrm{THz}(38$, $\left.54,58 \mathrm{~cm}^{-1}\right)$; acrylamide has two bands located at 1.44 and $2.00 \mathrm{THz}$ (48 and $67 \mathrm{~cm}^{-1}$ ); caprolactam has three bands at $1.24,1.66$ and $2.12 \mathrm{THz}\left(41,55\right.$ and $\left.71 \mathrm{~cm}^{-1}\right)$. The absorption bands of salicylamide are located at $1.44,1.63$, and $2.39 \mathrm{THz}$ $\left(48,54,80 \mathrm{~cm}^{-1}\right)$ at room temperature, and its bands have shifted to $1.46,1.66$, and $2.41 \mathrm{THz}\left(49,55\right.$ and $\left.80 \mathrm{~cm}^{-1}\right)$, and $1.22 \mathrm{THz}\left(41 \mathrm{~cm}^{-1}\right)$ band becomes clear at low temperature. For sulfanilamide, the bands are located at 1.63, 1.78, 2.00 and $2.20 \mathrm{THz}\left(54,59,67\right.$, and $\left.73 \mathrm{~cm}^{-1}\right)$. For these molecules, some of the peak positions are similar, for example, $1.63 \mathrm{THz}$ for benzamide, salicylamide, and sulfanilamide, $1.66 \mathrm{THz}$ for caprolactam; 1.22 and $1.24 \mathrm{THz}$ for salicylamide and caprolactam; $2.00 \mathrm{THz}$ for benzamide and sulfanilamide; 1.44 and $1.46 \mathrm{THz}$ for caprolactam and salicylamide, respectively. However, most of the bands are different in peak positions and relative intensities, which show that $\mathrm{THz}$ method is sensitive to different molecular structures.

To clarify the bands in the $\mathrm{THz}$ region, second derivatives have been performed using Omnic 5.0 software for the $\mathrm{THz}$ spectra of the samples, and the results show that main bands and some relatively minor bands are observed in the second derivatives results (shown in Figure 4). The main bands are observed for each sample, which has a good agreement with the corresponding $\mathrm{THz}$ absorption spectrum. For benzamide, only three main bands are observed, it is the same as 


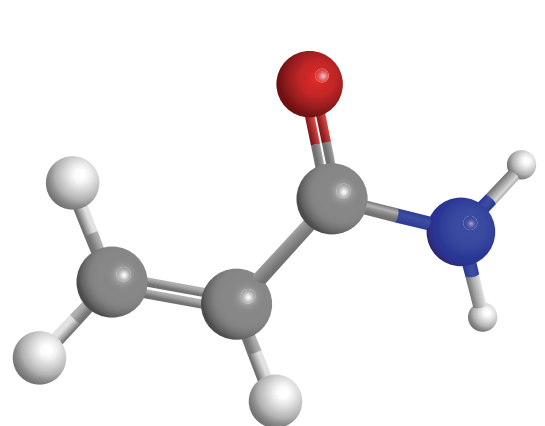

(a) Acrylamide

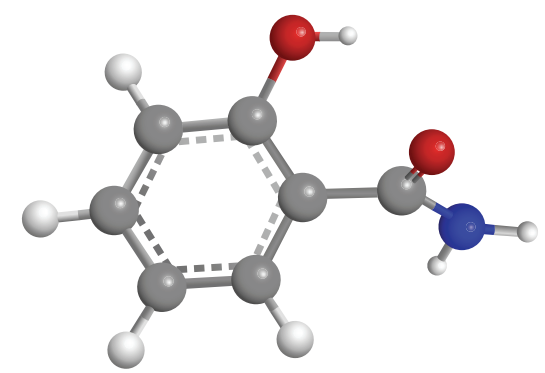

(c) Salicylamide

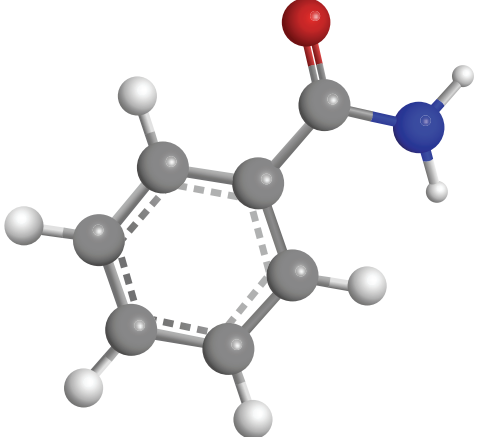

(b) Benzamide

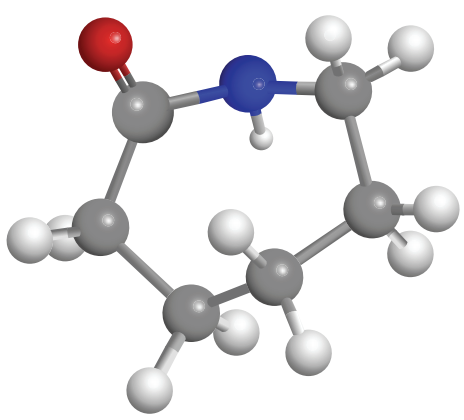

(d) Caprolactam

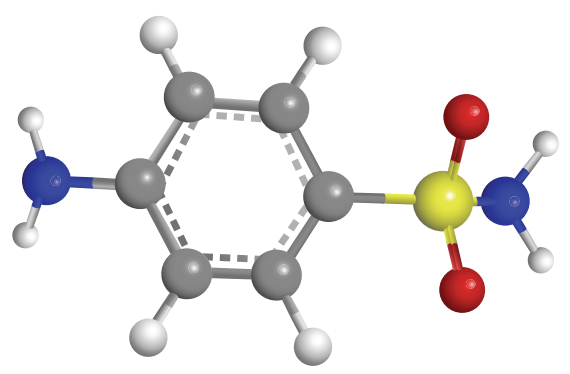

(e) Sulfanilamide

FiguRE 1: The molecular structures of acrylamide, benzamide, salicylamide, caprolactam, and sulfanilamide. (a) Acrylamide; (b) benzamide; (c) salicylamide; (d) caprolactam; (e) sulfanilamide.

the $\mathrm{THz}$ spectrum. For sulfanilamide, in the second derivatives results, $54,60,66,72,74,81 \mathrm{~cm}^{-1}$ are observed (54, 59,67 , and $73 \mathrm{~cm}^{-1}$ in the absorption spectrum), so $73 \mathrm{~cm}^{-1}$ band is formed by 72 and $74 \mathrm{~cm}^{-1}$ bands; for caprolactam, $71 \mathrm{~cm}^{-1}$ band is formed by 66,69 , and $71 \mathrm{~cm}^{-1}$ child-bands; for acrylamide, weak band at $48 \mathrm{~cm}^{-1}$ is emphasized in the second derivatives results, $67 \mathrm{~cm}^{-1}$ band mainly has several child-bands: $64,67,70,74$, and $82 \mathrm{~cm}^{-1}$; for salicylamide, 40 , $48,54,64,69,79 \mathrm{~cm}^{-1}$ bands are observed compared to 48 , 54 , and $80 \mathrm{~cm}^{-1}$ in the absorption spectrum. $40 \mathrm{~cm}^{-1}$ band is observed at low temperature. It seems that there is a band at $64 \mathrm{~cm}^{-1}$ for salicylamide. The results show that second derivatives methods help observing the $\mathrm{THz}$ bands.

3.2. The FIR Spectra of the Five Molecules with Amide Group. The FIR spectra of benzamide, acrylamide, caprolactam, salicylamide and sulfanilamide, after automatic baseline correction shown in Figure 3 indicate that the five molecules have different band positions and relative band intensities.

For salicylamide, it has many bands in the region: 608, $564,526,515,456,421,385,296,160,146,108$, and $93 \mathrm{~cm}^{-1}$. For benzamide, its bands are as follows: 635, 529, 412, 382, $251,177,151,110,89$, and $54 \mathrm{~cm}^{-1}$; for acrylamide, it has several bands in the region: $619,508,314,185,122$, and $67 \mathrm{~cm}^{-1}$; for caprolactam, it has relatively more bands in the region: 581, $503,488,398,337,323,258,195,129,87,69$, and $56 \mathrm{~cm}^{-1}$. Sulfanilamide has the bands located at $641,626,563,541$, $497,450,414,365,302,224,132,88,72$, and $58 \mathrm{~cm}^{-1}$ in its FIR spectrum. The FIR and THz results are consistent for the samples in the $100-50 \mathrm{~cm}^{-1}$ region as shown in Table 1 .

For benzamide and salicylamide, there is one $\mathrm{OH}$ difference. Their FIR spectra have various peak positions and relative intensities; only several peak positions are close, 

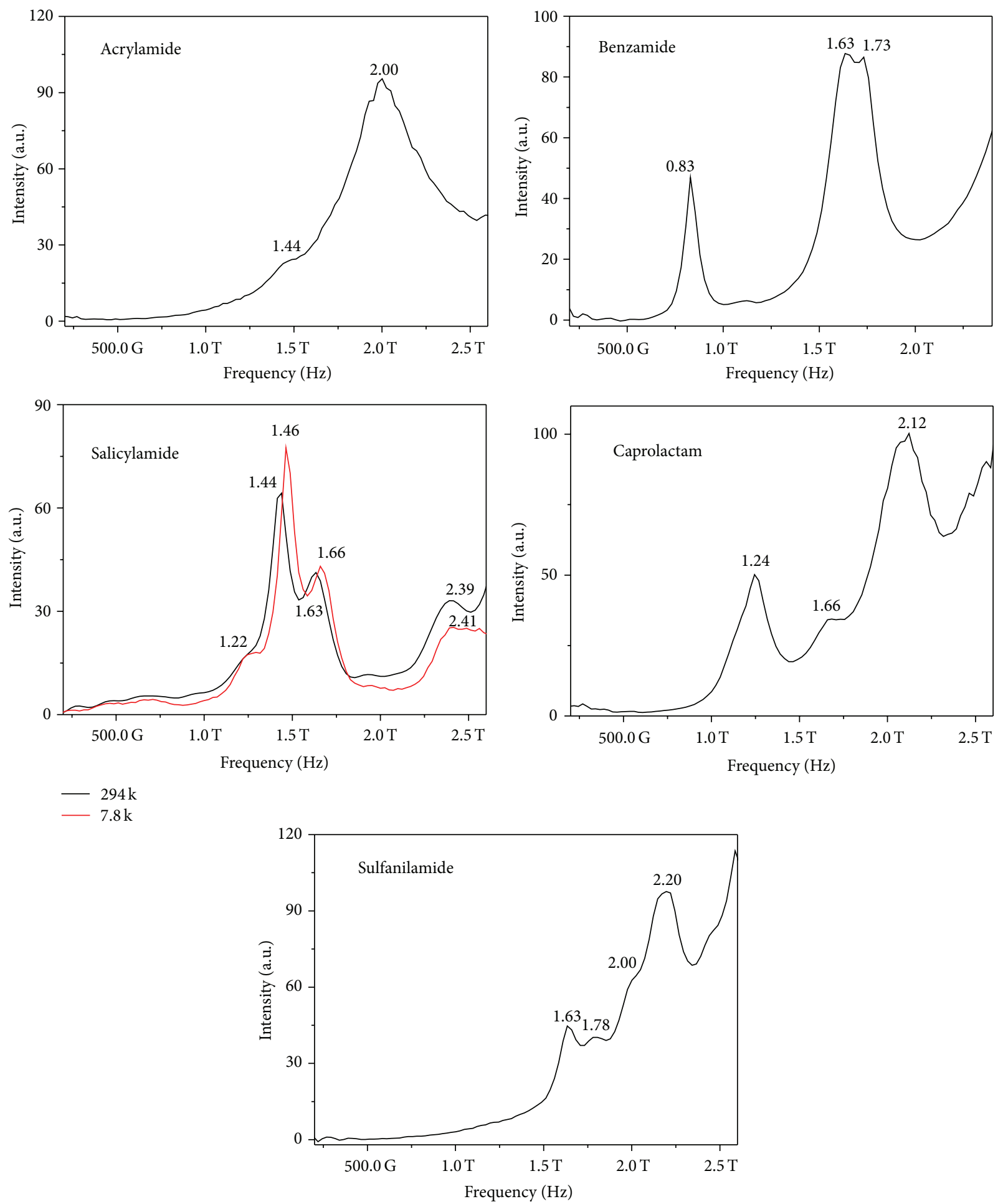

FIGURE 2: THz absorption spectra of acrylamide, benzamide, salicylamide, caprolactam, and sulfanilamide.

such as 529(benzamide)/526(salicylamide); 382/385; 151/146; $110 / 108 ; 89 / 93 \mathrm{~cm}^{-1}$. Other bands are located at different positions. For acrylamide and caprolactam, the bands at $508 / 503,314 / 323,185 / 195,122 / 129$, and $67 / 69 \mathrm{~cm}^{-1}$ are similar in some extent. Caprolactam has relatively more bands in the FIR region. Sulfanilamide has two strong bands located at 563 and $541 \mathrm{~cm}^{-1}$, and the band at $365 \mathrm{~cm}^{-1}$ is relatively strong, and other bands are weak. The five molecules have different characteristic bands in the FIR region.

3.3. DFT Calculation and Analyses for the FIR and THz Spectra of the Molecules. The assignment of the spectra in the FIR and 

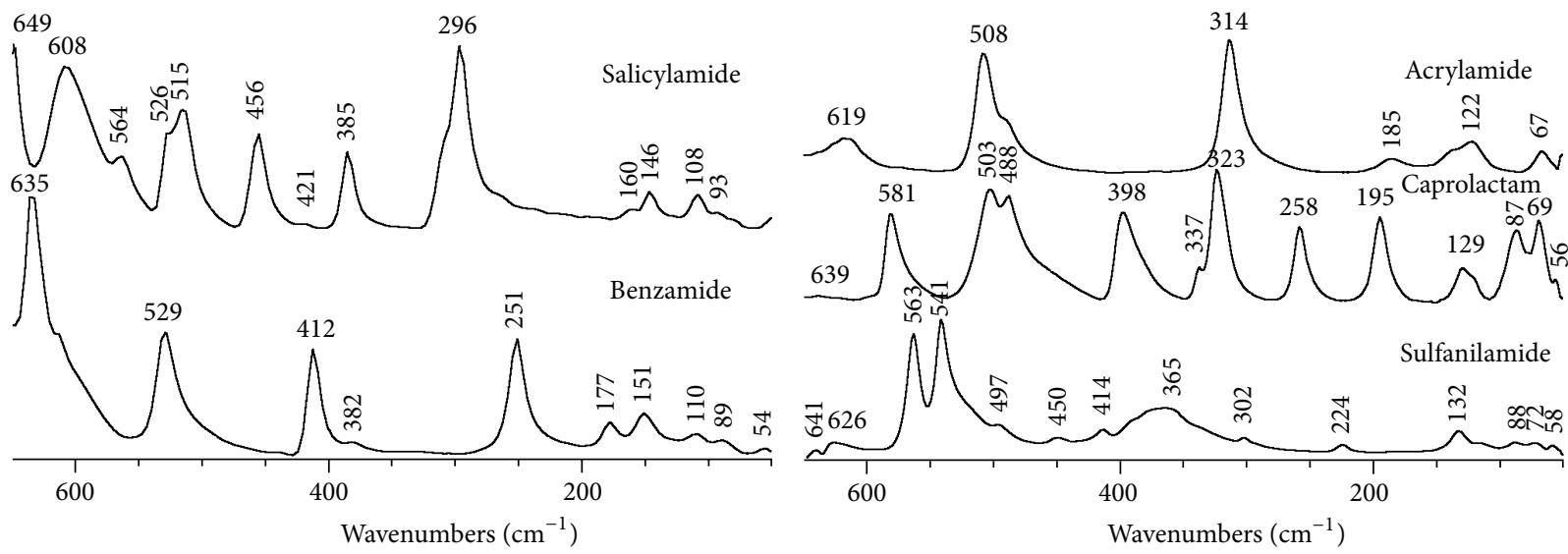

FIGURE 3: FIR spectra of acrylamide, benzamide, salicylamide, caprolactam, and sulfanilamide in the $650-50 \mathrm{~cm}^{-1} \mathrm{region}$.

THz region is difficult. Fortunately, there are some calculation results for benzamide, salicylamide, and sulfanilamide [3136]. Using similar method shown in the references, based on the calculated results of RB3LYP/6-311++G (3df, 2pd), and with the aid of visualization software of Gaussian View 4.1, the observed vibrational modes in the far-infrared and $\mathrm{THz}$ region can be assigned as shown in Table 1. The assignment is dependent on the result of calculation from molecular structure and patterns of vibrational modes. Some calculation results for the bands below $100 \mathrm{~cm}^{-1}$ are shown in Figure 5 . The calculated band positions are similar to experimental results in some extent as the calculations in [31-36], but the relative intensities of the bands compared to experimental results are not good as the calculation results for four vitamin molecules [37].

According to the DFT calculation results (shown in Table 1), the bands in the FIR and THz region mainly consist of movement of whole molecular skeleton. The absorption bands in the $\mathrm{THz}$ region are related to torsion, rocking, wagging, twisting, and other modes of different groups in the molecules. For example, in the calculation results, the main absorption bands of sulfanilamide below $100 \mathrm{~cm}^{-1}$ are centered at 15 and $85 \mathrm{~cm}^{-1}$. The $15 \mathrm{~cm}^{-1}$ band corresponds to out-of-plane wagging of ph ring and twisting of $\mathrm{NH}_{2}$ (the one in $\left.\mathrm{S}(=\mathrm{O})-\mathrm{NH}_{2}\right) ; 85 \mathrm{~cm}^{-1}$ band is related to out-of-plane wagging of ph ring and wagging of two $\mathrm{NH}_{2} ; 113 \mathrm{~cm}^{-1}$ band is related to rocking of $\mathrm{NH}_{2} ; 167 \mathrm{~cm}^{-1}$ band is related to deformation of $\mathrm{S}(=\mathrm{O})-\mathrm{NH}_{2}$ and in-plane wagging of $\mathrm{ph}$. For benzamide, $554 \mathrm{~cm}^{-1}$ band is assigned to twisting of $\mathrm{NH}_{2}$ and wagging of ph; $503 \mathrm{~cm}^{-1}$ band is assigned to in-plane wagging of ph and amide; $415 \mathrm{~cm}^{-1}$ band is assigned to outof-plane folding of ph ring; $375 \mathrm{~cm}^{-1}$ band is assigned to inplane rocking of amide, wagging of $\mathrm{ph}$, and stretching of CC. $341 \mathrm{~cm}^{-1}$ band is assigned to wagging of $\mathrm{NH}_{2} ; 217 \mathrm{~cm}^{-1}$ band is assigned to in-plane rocking of the ring, and rocking of $\mathrm{C}=\mathrm{O}-\mathrm{NH}_{2} ; 152 \mathrm{~cm}^{-1}$ band is assigned to out-of-plane vibration of ph ring and rocking of $\mathrm{NH}_{2} ; 57 \mathrm{~cm}^{-1}$ band is assigned to out-of-plane vibration of $\mathrm{ph}-\mathrm{CONH}_{2}$ and wagging of $\mathrm{NH}_{2}$.

For salicylamide, $30 \mathrm{~cm}^{-1}$ band is assigned to twisting of ph-CONH${ }_{2} ; 141 \mathrm{~cm}^{-1}$ band is assigned to out-of-plane vibration of whole molecule; $184 \mathrm{~cm}^{-1}$ band is assigned to wagging of $\mathrm{NH}_{2} ; 247 \mathrm{~cm}^{-1}$ band is assigned to out-of-plane wagging of whole molecule, especially ph ring; $275 \mathrm{~cm}^{-1}$ band is assigned to rocking of $\mathrm{NH}_{2}$, rocking of $\mathrm{ph} ; 383 \mathrm{~cm}^{-1}$ band is assigned to in-plane vibration of $\mathrm{ph}$ and torsion of $\left(\mathrm{C}=\mathrm{O}-\mathrm{NH}_{2}\right.$ and $\left.\mathrm{COH}\right) ; 419 \mathrm{~cm}^{-1}$ band is assigned to out-ofplane folding of ph and stretching of $\mathrm{NH} ; 439 \mathrm{~cm}^{-1}$ band is assigned to in-plane wagging of ph; twisting of $\left(\mathrm{C}=\mathrm{O}-\mathrm{NH}_{2}\right.$ and $\mathrm{COH}$ ); $509 \mathrm{~cm}^{-1}$ band is assigned to rocking of $\mathrm{NH}_{2}$, rocking of $(\mathrm{C}=\mathrm{O}$ and $\mathrm{OH})$, in-plane wagging of $\mathrm{ph}$, and so forth. For acrylamide, $114 \mathrm{~cm}^{-1}$ band is assigned to wagging of $\mathrm{NH}_{2}$ and wagging of $\mathrm{CH}=\mathrm{CH}_{2} ; 190 \mathrm{~cm}^{-1}$ band is assigned to wagging of $\mathrm{NH}_{2} ; 277 \mathrm{~cm}^{-1}$ band is assigned to rocking of $\left(\mathrm{CH}=\mathrm{CH}_{2}\right)$ and rocking of $\left(\mathrm{C}=\mathrm{O}-\mathrm{NH}_{2}\right) ; 468 \mathrm{~cm}^{-1}$ band is assigned to rocking of $\mathrm{NH}_{2}$ and wagging of $\left(\mathrm{CH}=\mathrm{CH}_{2}\right)$; $470 \mathrm{~cm}^{-1}$ band is assigned to twisting of $\left(\mathrm{CH}=\mathrm{CH}_{2}\right)$ and twisting of $\mathrm{NH}_{2} ; 613 \mathrm{~cm}^{-1}$ band is assigned to twisting of $\mathrm{NH}_{2}$ and twisting of $\mathrm{CH}_{2}$, and so forth. For caprolactam, $107 \mathrm{~cm}^{-1}$ band is assigned to wagging of $\mathrm{CH}_{2}$, stretching of $\mathrm{C}=\mathrm{O}$, and out-of-plane vibration of the ring; $158 \mathrm{~cm}^{-1}$ band is assigned to rocking of $\mathrm{CH}_{2}$ and in-plane vibration of the ring; $258 \mathrm{~cm}^{-1}$ band is assigned to rocking of $\mathrm{CH}_{2}$, wagging of $\mathrm{CH}_{2}$, stretching of $\mathrm{NH}$, stretching of $\mathrm{C}=\mathrm{O}$, and so forth; $301 \mathrm{~cm}^{-1}$ band is assigned to stretching of $\mathrm{NH}$ and in-plane vibration of the ring; $323 \mathrm{~cm}^{-1}$ band is assigned to rocking of $\mathrm{CH}_{2} ; 402 \mathrm{~cm}^{-1}$ band is assigned to in-plane vibration of the ring, and so forth. In most of the cases whole molecule is involved in the vibration modes. The calculation results are similar in some extent to the results in [31-37]. The calculations in Table 1 are only preliminary results, because only single molecule and in gas phase have been considered here, so it is reasonable that the calculation and experimental results have some differences. 
TABLE 1: Calculated and experimental vibrational frequencies for salicylamide, benzamide, acrylamide, caprolactam, and sulfanilamide $\left(\mathrm{cm}^{-1}\right)^{\mathrm{a}}$.

\begin{tabular}{|c|c|c|c|c|}
\hline \multirow{2}{*}{ Compounds } & \multicolumn{2}{|c|}{ Experiment } & \multirow{2}{*}{$\begin{array}{c}\text { Calculation } \\
6-311++G(3 d f, 2 p d)\end{array}$} & \multirow{2}{*}{ Vibrational assignments } \\
\hline & FIR & THz-TDS & & \\
\hline \multirow{15}{*}{ Salicylamide } & 526 & & 538 & $\tau \mathrm{ph}$ \\
\hline & 515 & & 509 & $\rho \mathrm{NH}_{2}, \rho(\mathrm{C}=\mathrm{O}$ and $\mathrm{OH})$, in-plane wagging of ph \\
\hline & 456 & & 439 & In-plane wagging of $\mathrm{ph}, \mathrm{t}\left(\mathrm{C}=\mathrm{O}-\mathrm{NH}_{2}\right.$ and $\left.\mathrm{COH}\right)$ \\
\hline & & & 419 & Out-of-plane folding of ph, $\nu \mathrm{NH}$ \\
\hline & 385 & & 383 & $\beta \mathrm{ph}, \tau\left(\mathrm{C}=\mathrm{O}-\mathrm{NH}_{2}\right.$ and $\left.\mathrm{COH}\right)$ \\
\hline & 296 & & 275 & $\rho \mathrm{NH}_{2}, \rho(\mathrm{ph})$ \\
\hline & & & 247 & Out-of-plane wagging of whole molecule, especially ph ring \\
\hline & 161 & & 184 & $\omega \mathrm{NH}_{2}$ \\
\hline & 146 & & & \\
\hline & 108 & & 141 & $\gamma($ whole molecule $)$ \\
\hline & 94 & & & \\
\hline & & 80 & & \\
\hline & & $54\left(55^{*}\right)$ & & \\
\hline & & $48\left(49^{*}\right)$ & & \\
\hline & & $41^{*}$ & 30 & $\mathrm{t}\left(\mathrm{ph}-\mathrm{C}=\mathrm{O}-\mathrm{NH}_{2}\right)$ \\
\hline \multirow{13}{*}{ Benzamide } & & & 503 & In-plane wagging of ph and amide \\
\hline & & & 415 & Out-of-plane folding of ph ring \\
\hline & 412 & & 414 & Out-of-plane folding of ph ring, $\rho \mathrm{NH}_{2}$ \\
\hline & 383 & & 375 & In-plane rocking of amide group, $\omega \mathrm{ph}, \nu \mathrm{CC}$ \\
\hline & & & 341 & $\omega \mathrm{NH}_{2}$ \\
\hline & 251 & & 217 & In-plane rocking of ph ring, $\rho\left(\mathrm{C}=\mathrm{O}-\mathrm{NH}_{2}\right)$ \\
\hline & 178 & & & \\
\hline & 151 & & 152 & $\gamma \mathrm{ph} ; \rho \mathrm{NH}_{2}$ \\
\hline & 110 & & & \\
\hline & 90 & & & \\
\hline & & 58 & & \\
\hline & 54 & 54 & 57 & $\gamma\left(\mathrm{ph}-\mathrm{CONH}_{2}\right), \omega \mathrm{NH}_{2}$ \\
\hline & & 38 & & \\
\hline \multirow{7}{*}{ Acrylamide } & 508 & & 470 & $\mathrm{t}\left(\mathrm{CH}=\mathrm{CH}_{2}\right), \mathrm{tNH}_{2}$ \\
\hline & & & 468 & $\rho \mathrm{NH}_{2}, \omega\left(\mathrm{CH}=\mathrm{CH}_{2}\right)$ \\
\hline & 314 & & 277 & $\rho\left(\mathrm{CH}=\mathrm{CH}_{2}\right), \rho\left(\mathrm{C}=\mathrm{O}-\mathrm{NH}_{2}\right)$ \\
\hline & 185 & & 190 & $\omega \mathrm{NH}_{2}$ \\
\hline & 122 & & 114 & $\omega \mathrm{NH}_{2}, \omega\left(\mathrm{CH}=\mathrm{CH}_{2}\right)$ \\
\hline & 67 & 67 & & \\
\hline & & 48 & & \\
\hline \multirow{12}{*}{ Caprolactam } & 503 & & 508 & $\nu \mathrm{NH} ; \rho \mathrm{CH}_{2}$ \\
\hline & 488 & & 437 & $\nu \mathrm{C}=\mathrm{O} ; \nu \mathrm{NH} ; \omega \mathrm{CH}_{2}$ \\
\hline & 398 & & 402 & $\beta$ ring \\
\hline & 337 & & 323 & $\rho \mathrm{CH}_{2}$ \\
\hline & 323 & & 301 & $\nu \mathrm{NH} ; \beta$ ring \\
\hline & 258 & & 258 & $\rho \mathrm{CH}_{2} ; \omega \mathrm{CH}_{2} ; \nu \mathrm{NH} ; \nu \mathrm{C}=\mathrm{O}$ \\
\hline & 195 & & 158 & $\rho \mathrm{CH}_{2}, \beta$ ring \\
\hline & 129 & & 107 & $\omega \mathrm{CH}_{2} ; \nu \mathrm{C}=\mathrm{O} ; \gamma$ ring \\
\hline & 87 & & & \\
\hline & 69 & 71 & & \\
\hline & 56 & 55 & & \\
\hline & & 41 & & \\
\hline
\end{tabular}


TABle 1: Continued.

\begin{tabular}{|c|c|c|c|c|}
\hline \multirow{2}{*}{ Compounds } & \multicolumn{2}{|c|}{ Experiment } & Calculation & \multirow{2}{*}{ Vibrational assignments } \\
\hline & FIR & THz-TDS & $6-311++G(3 d f, 2 p d)$ & \\
\hline \multirow{4}{*}{ Sulfanilamide } & & 73 & 85 & Out-of-plane wagging of ph, $\omega \mathrm{NH}_{2}$ \\
\hline & & 67 & & \\
\hline & & 59 & & \\
\hline & & 54 & 15 & Out-of-plane wagging of $\mathrm{ph}, \mathrm{tNH}_{2}$ \\
\hline
\end{tabular}

${ }^{\mathrm{a}} \beta$ : in-plane vibration; $\tau$ : torsion; $\gamma$ : out-of-plane vibration; $\nu$ : stretching; $\omega$ : wagging; $\rho$ : rocking; t: twisting, ph: benzene ring.
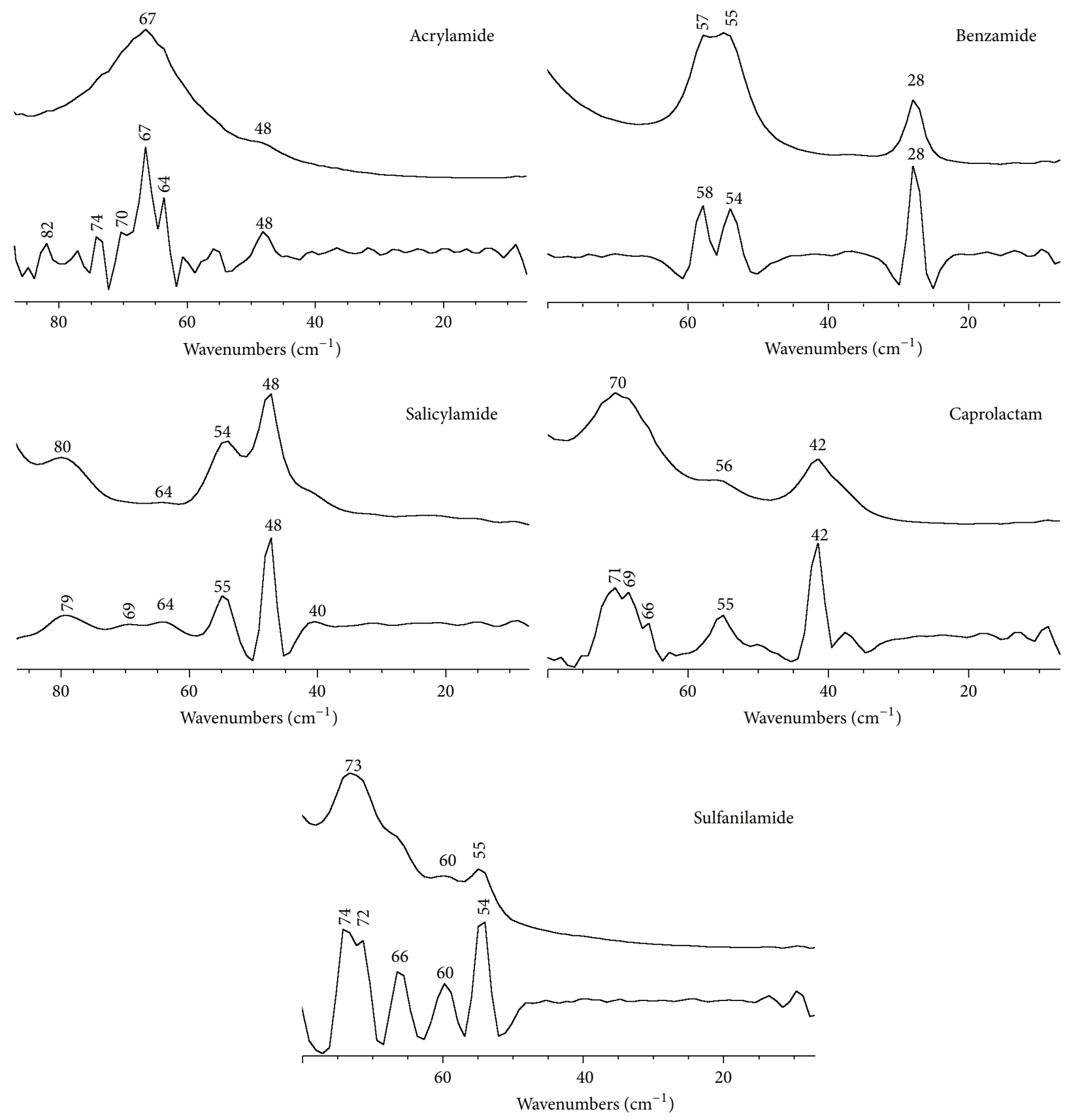

FIGURE 4: The second derivatives results for the THz spectra of the samples using Omnic 5.0 software. 


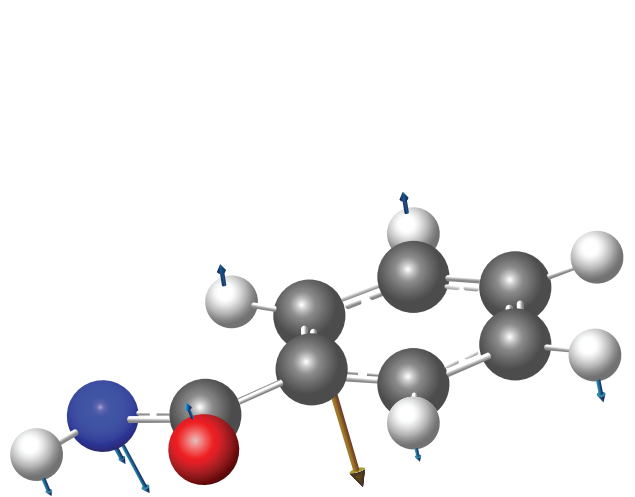

(a) $57 \mathrm{~cm}^{-1}$ for benzamide

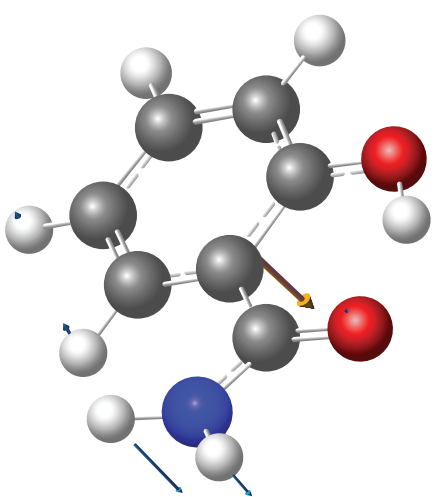

(b) $30 \mathrm{~cm}^{-1}$ for salicylamide

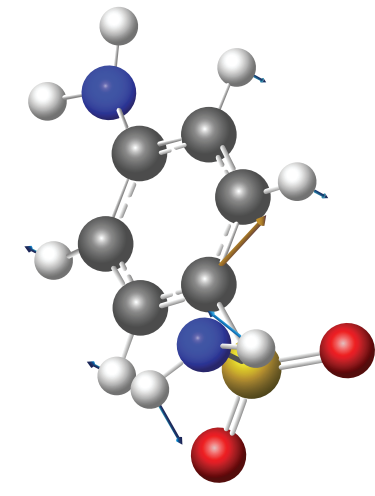

(c) $15 \mathrm{~cm}^{-1}$ for sulfanilamide

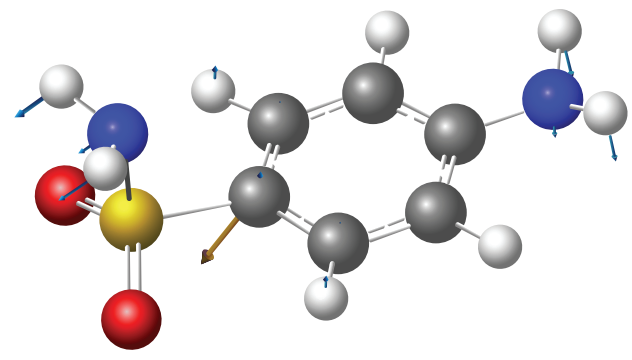

(d) $85 \mathrm{~cm}^{-1}$ for sulfanilamide

FIGURE 5: Low-frequency vibrational modes of the molecules below $100 \mathrm{~cm}^{-1}$. (a) $57 \mathrm{~cm}^{-1}$ for benzamide; (b) $30 \mathrm{~cm}^{-1}$ for salicylamide; (c) $15 \mathrm{~cm}^{-1}$ for sulfanilamide; (d) $85 \mathrm{~cm}^{-1}$ for sulfanilamide.

\section{Conclusions}

The FIR and THz characteristic bands of five molecules with amide groups are observed using FIR and terahertz time-domain spectroscopy. The five molecules exhibit several bands in the $\mathrm{THz}$ region, which may be related to torsion, rocking, wagging, and other modes of different groups in the molecules according to calculation and the assignments in the references. $\mathrm{THz}$ spectra are effective method to distinguish different molecules with amide groups. In addition, it is also the basis for investigation on hydration of amide group, and so forth.

\section{Conflict of Interests}

The authors declare that there is no conflict of interests regarding the publication of this paper.

\section{Acknowledgments}

The authors gratefully acknowledge the financial support by National Natural Science Foundation of China for the Grants (21001009 and 50973003), the State Key Project for Fundamental Research of MOST (2011CB808304), National High-tech R\&D Program of China (863 Program) of MOST
(2010AA03A406), and the Scientific Research Project of Beijing Municipal Commission of Education and Beijing Natural Science Foundation (Grant no. KZ201310028032). Limin Yang is one of the corresponding authors.

\section{References}

[1] S. G. Liu, "Recent development of terahertz science and technology," China Basic Science, vol. 1, pp. 7-12, 2006.

[2] M. C. Beard, G. M. Turner, and C. A. Schmuttenmaer, "Terahertz spectroscopy," Journal of Physical Chemistry B, vol. 106, no. 29, pp. 7146-7159, 2002.

[3] M. C. Kemp, P. F. Taday, B. E. Cole, J. A. Cluff, A. J. Fitzgerald, and W. R. Tribe, "Security applications of terahertz technology," in Terahertz for Military and Security Applications, Proceedings of SPIE, pp. 44-52, April 2003.

[4] M. R. Leahy-Hoppa, M. J. Fitch, and R. Osiander, "Terahertz spectroscopy techniques for explosives detection," Analytical and Bioanalytical Chemistry, vol. 395, no. 2, pp. 247-257, 2009.

[5] A. G. Davies, A. D. Burnett, W. Fan, E. H. Linfield, and J. E. Cunningham, "Terahertz spectroscopy of explosives and drugs," Materials Today, vol. 11, no. 3, pp. 18-26, 2008.

[6] P. M. Hakey, M. R. Hudson, D. G. Allis, W. Ouellette, and T. M. Korter, "Examination of phencyclidine hydrochloride via cryogenic terahertz spectroscopy, solid-state density functional 
theory, and X-ray diffraction," Journal of Physical Chemistry A, vol. 113, no. 46, pp. 13013-13022, 2009.

[7] C. J. Strachan, T. Rades, D. A. Newnham, K. C. Gordon, M. Pepper, and P. F. Taday, "Using terahertz pulsed spectroscopy to study crystallinity of pharmaceutical materials," Chemical Physics Letters, vol. 390, no. 1-3, pp. 20-24, 2004.

[8] P. F. Taday, I. V. Bradley, D. D. Arnone, and M. Pepper, "Using Terahertz pulse spectroscopy to study the crystalline structure of a drug: a case study of the polymorphs of ranitidine hydrochloride," Journal of Pharmaceutical Sciences, vol. 92, no. 4, pp. 831-838, 2003.

[9] L. J. Xie, Y. Yao, and Y. B. Ying, "The application of terahertz spectroscopy to protein detection: a review," Applied Spectroscopy Reviews, vol. 49, no. 6, pp. 448-461, 2014.

[10] B. Born, H. Weingärtner, E. Bründermann, and M. Havenith, "Solvation dynamics of model peptides probed by terahertz spectroscopy. observation of the onset of collective network motions," Journal of the American Chemical Society, vol. 131, no. 10, pp. 3752-3755, 2009.

[11] M. V. Tsurkan, N. S. Balbekin, E. A. Sobakinskaya, A. N. Panin, and V. L. Vaks, "Terahertz spectroscopy of DNA," Optics and Spectroscopy, vol. 114, pp. 894-898, 2013.

[12] T. M. Korter, R. Balu, M. B. Campbell, M. C. Beard, S. K. Gregurick, and E. J. Heilweil, "Terahertz spectroscopy of solid serine and cysteine," Chemical Physics Letters, vol. 418, no. 1-3, pp. 65-70, 2006.

[13] L. Yang, G. Zhao, W. Li et al., "Low-frequency vibrational modes of dl-homocysteic acid and related compounds," Spectrochimica Acta Part A, vol. 73, no. 5, pp. 884-891, 2009.

[14] L. Yang, H. Sun, S. Weng et al., "Terahertz absorption spectra of some saccharides and their metal complexes," Spectrochimica Acta Part A, vol. 69, no. 1, pp. 160-166, 2008.

[15] D. F. Plusquellic, K. Siegrist, E. J. Heilweil, and O. Esenturk, "Applications of terahertz spectroscopy in biosystems," ChemPhysChem, vol. 8, no. 17, pp. 2412-2431, 2007.

[16] B. Born, S. J. Kim, S. Ebbinghaus, M. Gruebele, and M. Havenith, "The terahertz dance of water with the proteins: the effect of protein flexibility on the dynamical hydration shell of ubiquitin," Faraday Discussions, vol. 141, pp. 161-173, 2008.

[17] B. Born and M. Havenith, "Terahertz dance of proteins and sugars with water," Journal of Infrared, Millimeter, and Terahertz Waves, vol. 30, no. 12, pp. 1245-1254, 2009.

[18] H. H. Mantsch and D. Naumann, "Terahertz spectroscopy: the renaissance of far infrared spectroscopy," Journal of Molecular Structure, vol. 964, no. 1-3, pp. 1-4, 2010.

[19] N. C. Comelli, N. E. Massa, E. A. Castro, and A. H. Jubert, "Spectroscopy properties of the amide group in valpromide and some derivatives with antiepileptic activity," Journal of Raman Spectroscopy, vol. 40, no. 12, pp. 1797-1809, 2009.

[20] K. M. Gough, L. Tzadu, M. Z. Kastyak, A. C. Kuzyk, and R. L. Julian, "Theoretical and experimental considerations for interpretation of amide I bands in tissue," Vibrational Spectroscopy, vol. 53, no. 1, pp. 71-76, 2010.

[21] H. Maekawa and N.-H. Ge, "Comparative study of electrostatic models for the amide-I and -II modes: linear and twodimensional infrared spectra," Journal of Physical Chemistry B, vol. 114, no. 3, pp. 1434-1446, 2010.

[22] A. S. Kutsenko, R. A. Motiyenko, L. Margules, and J. C. Guillemin, "The extended spectroscopic database for deuterated species of formamide up to $1 \mathrm{THz}$," Astronomy and Astrophysics, vol. 549, article A128, 4 pages, 2013.
[23] C.-S. Su and Y.-P. Chen, "Recrystallization of salicylamide using a batch supercritical antisolvent process," Chemical Engineering and Technology, vol. 28, no. 10, pp. 1177-1181, 2005.

[24] V. O. Sheftel, Indirect Food Additives and Polymers: Migration and Toxicology, Lewis, London, UK, 2000.

[25] A. S. R. Duarte, A. M. Amorim Da Costa, and A. M. Amado, "On the conformation of neat acrylamide dimers-a study by ab initio calculations and vibrational spectroscopy," Journal of Molecular Structure: THEOCHEM, vol. 723, no. 1-3, pp. 63-68, 2005.

[26] R. J. Falconer and A. G. Markelz, "Terahertz spectroscopic analysis of peptides and proteins," Journal of Infrared, Millimeter, and Terahertz Waves, vol. 33, no. 10, pp. 973-988, 2012.

[27] Y. Hu, X.-H. Wang, L.-T. Guo, C.-L. Zhang, H.-B. Liu, and X.-C. Zhang, "Absorption and dispersion of vegetable oil and animal fat in THz range," Acta Physica Sinica, vol. 54, no. 9, pp. 41244128, 2005.

[28] M. J. Frisch, G. W. Trucks, H. B. Schlegel, C. Gonzalez, and J. A. Pople, Gaussian 03, Revision C.02, Gaussian, Inc., Wallingford, Conn, USA, 2004.

[29] P. J. Stephens, F. J. Devlin, C. F. Chabalowski, and M. J. Frisch, "Ab Initio calculation of vibrational absorption and circular dichroism spectra using density functional force fields," Journal of Physical Chemistry, vol. 98, no. 45, pp. 11623-11627, 1994.

[30] R. Krishnan, J. S. Binkley, R. Seeger, and J. A. Pople, "Selfconsistent molecular orbital methods. XX. A basis set for correlated wave functions," The Journal of Chemical Physics, vol. 72, no. 1, pp. 650-654, 1980.

[31] J. Palomar, J. L. G. De Paz, and J. Catalán, "Vibrational study of intramolecular hydrogen bonding in o-hydroxybenzoyl compounds," Chemical Physics, vol. 246, no. 1-3, pp. 167-208, 1999.

[32] N. Sundaraganesan, N. Puviarasan, and S. Mohan, "Vibrational spectra, assignments and normal coordinate calculation of acrylamide," Talanta, vol. 54, no. 2, pp. 233-241, 2001.

[33] H. T. Varghese, C. Y. Panicker, and D. Philip, "Vibrational spectroscopic studies and ab initio calculations of sulfanilamide," Spectrochimica Acta Part A, vol. 65, no. 1, pp. 155-158, 2006.

[34] C. Topacli and A. Topacli, "Semi-empirical infrared spectra simulations of metal complexes of sulfanilamide," Journal of Molecular Structure, vol. 654, no. 1-3, pp. 153-159, 2003.

[35] C. Topacli and A. Topacli, "Ab initio calculations and vibrational structure of sulfanilamide," Journal of Molecular Structure, vol. 644, no. 1-3, pp. 145-150, 2003.

[36] G. Ogruc Ildiz and S. Akyuz, "Conformational analysis and vibrational study of sulfanilamide," Vibrational Spectroscopy, vol. 58, pp. 12-18, 2012.

[37] G. Z. Zhao, B. Yu, and C. L. Zhang, "Terahertz spectroscopic investigation of four kinds of vitamins," Journal of Applied Physics, vol. 106, Article ID 104702, 5 pages, 2009. 

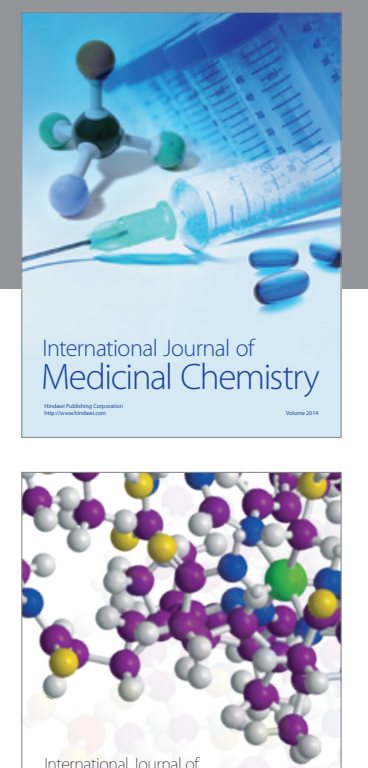

\section{Carbohydrate} Chemistry

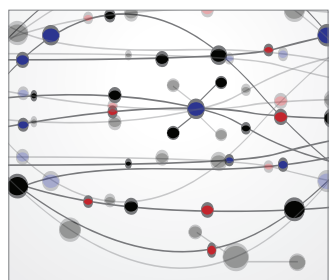

The Scientific World Journal
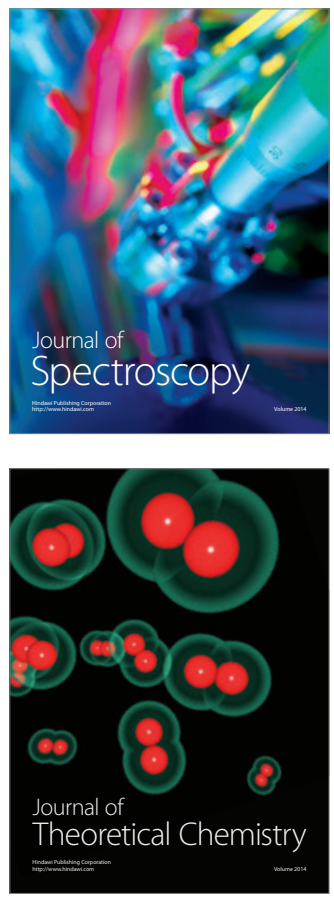
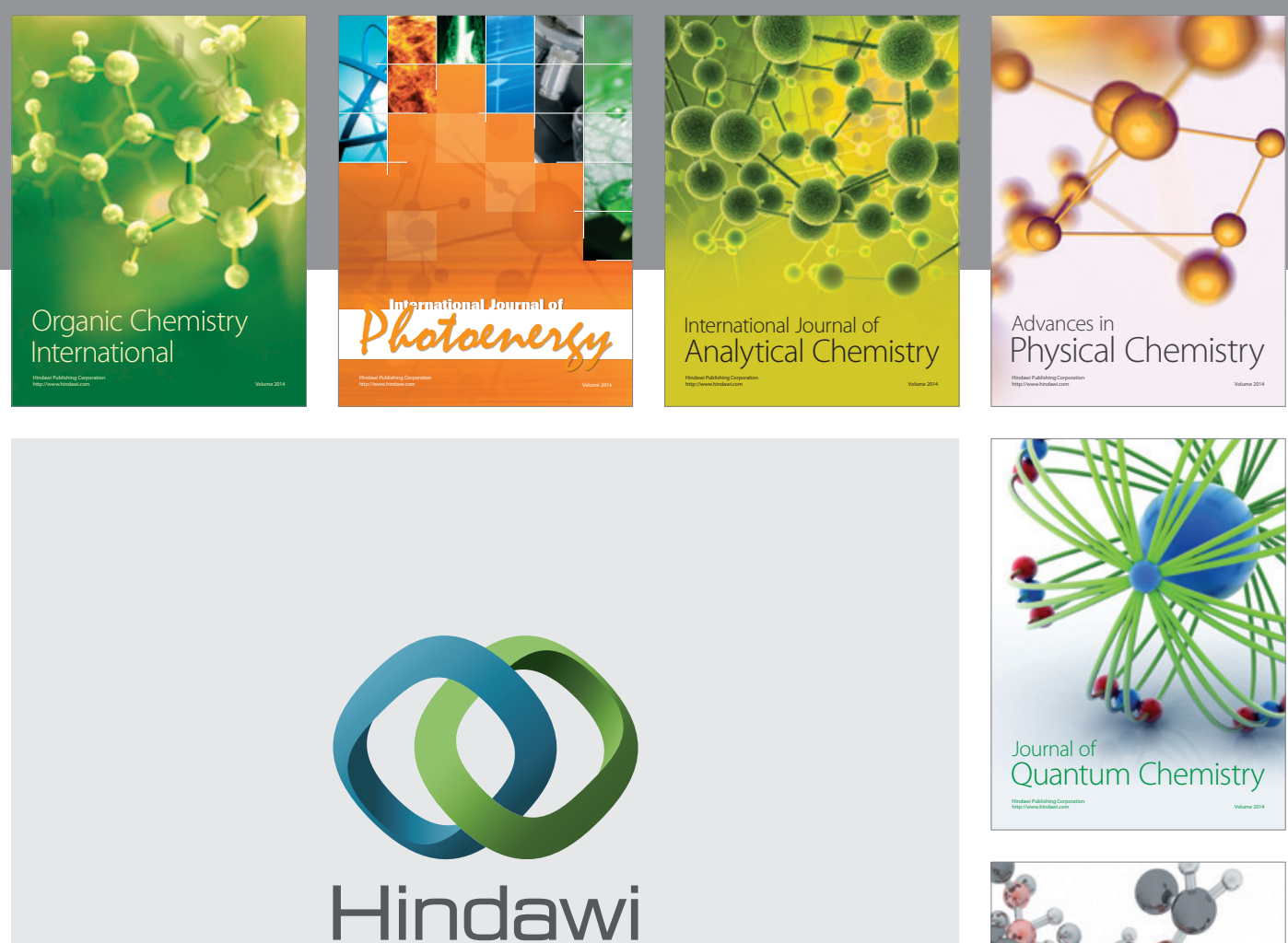

Submit your manuscripts at

http://www.hindawi.com

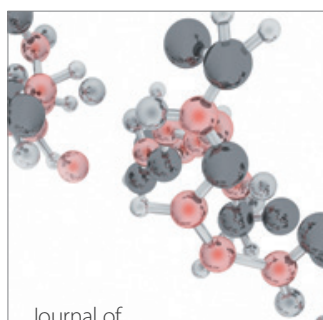

Analytical Methods

in Chemistry

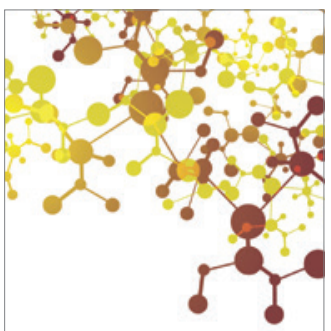

Journal of

Applied Chemistry

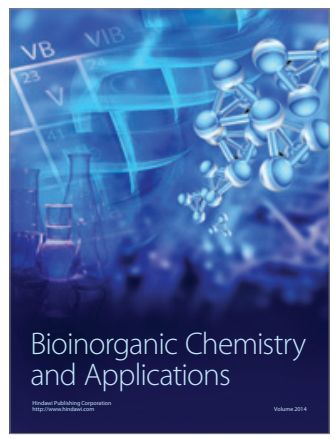

Inorganic Chemistry
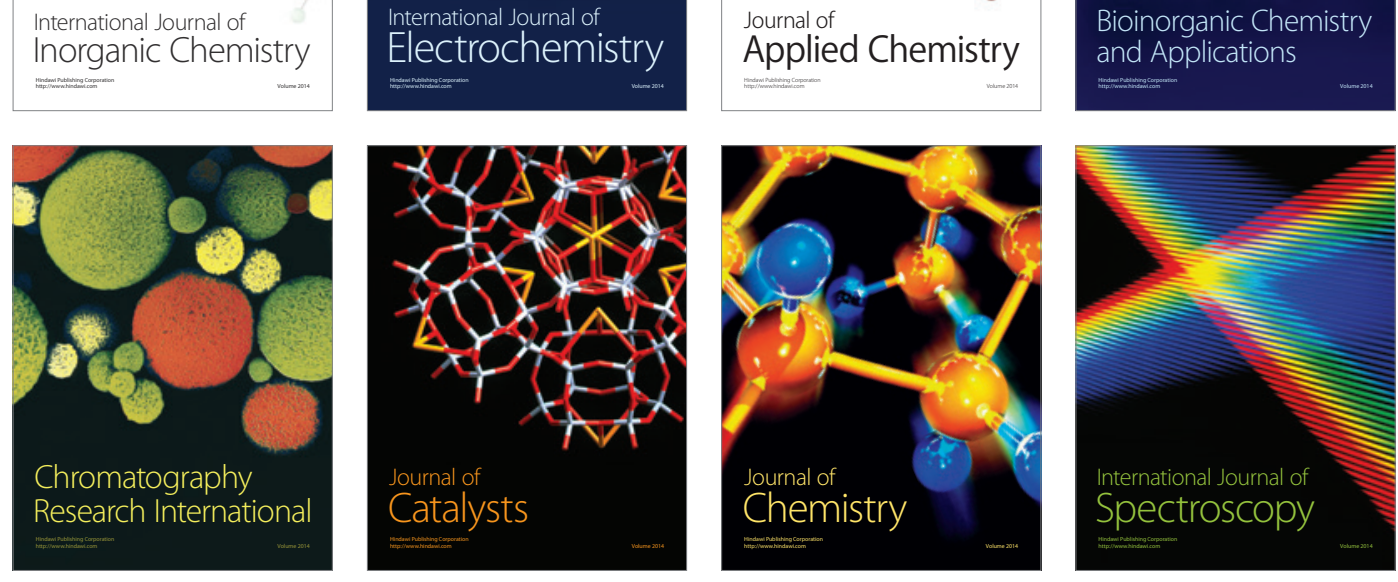